\title{
Improving Peripheral and Central Vascular Adjustments during Exercise through a Training Program in Adolescents with Obesity
}

\author{
Valérie Julian $^{a, b}$ David Thivel ${ }^{c}$ Bruno Pereira $^{d}$ Frédéric Costes $^{a}$ \\ Ruddy Richard ${ }^{a}$ Martine Duclos ${ }^{a}$ \\ a Department of Sport Medicine and Functional Explorations, University Hospital of \\ Clermont-Ferrand, Clermont-Ferrand, France; ${ }^{b}$ Department of Pediatrics, University Hospital \\ of Clermont-Ferrand, Clermont-Ferrand, France; ${ }^{C}$ AME2P Laboratory, Bat Bio B, Campus \\ Universitaire des Cezeaux, Aubiere Cedex. France; ${ }^{d}$ Biostatistics Unit (Department of Clinical \\ Research and Innovation), University Hospital of Clermont-Ferrand, Clermont-Ferrand, France
}

\section{Key Words}

Childhood obesity $\cdot$ Exercise $\cdot$ Insulin resistance $\cdot$ Microvasculature $\cdot$ Physical activity

\begin{abstract}
Objective: The effects of a training program (TP) on muscle microvascularization during exercise remained to be explored in adolescents with obesity. We hypothesized that a TP would lead to better microvascular adaptations to exercise in skeletal muscle. Methods: 15 inactive adolescents followed a 12-week TP where both peripheral (muscular microvascularization) and central (cardiac) adaptations to exercise ( 40 min exercise set at $70 \% \dot{\mathrm{V}}_{2 \text { peak }}$ ) were assessed before and after intervention. Microvascular adaptations were evaluated in the Musculus vastus lateralis with near-infrared spectroscopy, by measurement of muscular blood volume (IR-BV) and tissue oxygen saturation ( $\left(\mathrm{R}-\mathrm{SO}_{2}\right)$. Central adaptations were evaluated using thoracic impedance. Results: The TP favored lower BMI ( $p<0.001)$, lower total and abdominal fat $(p<0.001)$, and a trend for the decrease in insulin resistance index $(p=0.07)$. $\dot{\mathrm{V}} \mathrm{O}_{2 \text { peak }}$ relative to weight $(\mathrm{p}=0.008)$ and maximum power output increased $(p=0.0003)$. A smaller initial drop in IR-BV and IR-SO $2(p<0.001)$, a prompter return of these parameters to their base values, and a higher IR-BV and IR-SO ${ }_{2}$ all times taken together $(p<0.001)$ were observed after completing the TP. Concerning central adaptation, cardiac output decreased $(p<0.001)$. Conclusion: We demonstrate for the first time by noninvasive techniques that a training program induces peripheral and central vascular adaptations to exercise in adolescents with obesity.


Julian et al.: Improving Peripheral and Central Vascular Adjustments during Exercise through a Training Program in Adolescents with Obesity

\section{Introduction}

Obesity in adolescents is associated with comorbidities such as cardiovascular diseases, and the treatment of this pediatric vascular disorder remains a major public health challenge [1]. There is a linear relationship between adolescent obesity and cardiovascular risks in adulthood regardless of weight evolution [2]. In addition, early vascular dysfunction has been correlated with morbidity and mortality linked to adult atherosclerosis [3]. Physical activity (PA), given its well-documented metabolic and vascular effects, is now an integral part of healthcare directed at childhood obesity, in addition to dietary measures [4].

It has been demonstrated that both exercise and insulin play a part in increasing muscle microvascularization [5]. With exercise, the increased metabolic demand of muscle requires a cardiovascular adaptation both peripherally (muscle microvascularization) and centrally (cardiac microvascularization). The peripheral component involves both muscle capillary recruitment and arteriolar dilatation, in order to increase the blood flow and meet the demand for oxygen and nutrients by the muscles at work [5]. Insulin also increases the exchange surface area between plasma and muscle insterstitium by arteriolar vasodilatation [5] through a nitric oxide-dependent mechanism [6, 7]. Thus, in insulin-sensitive subjects, postprandial physiological hyperinsulinemia increases blood flow to permit a better distribution of nutrients [5]. This postprandial adaptation mechanism is not evidenced in insulin-resistant subjects with obesity [8]. During exercise, insulin resistance associated with obesity would set a limit to vascular adaptations, hence to the delivery of oxygen and nutrients to the muscles [9].

A relationship between PA and insulin resistance has been shown in adolescent subjects, regardless of any weight loss, with a significant decrease in insulin resistance after a 8-week training program (TP) [10-12].

The impact of physical training on microvascular adaptations during exercise has not yet been explored in pediatrics due to the invasiveness of the methods used to measure microvascularization. We hypothesized that a combined 12-week TP would improve muscle oxygenation through microvascularization adaptations during exercise in adolescents with obesity. Our main goal was to use noninvasive techniques to assess training-induced microvascular adaptations to exercise. A secondary goal was to explore the relationship between lowering of insulin resistance and microvascular adaptations to exercise.

\section{Subjects and Methods}

\section{Subjects}

15 inactive (<10 MET-h/week [13]) adolescents aged 12-16 years (Tanner stage $3-5$ ), with BMI > 97th percentile according to the French reference curves [14] were included at the time of admission in a home for obese children (Centre Médical Infantile, Romagnat, France). Recent weight loss (last 2 months), medication affecting energy metabolism, regular tobacco or alcohol use, and any medical condition precluding PA were considered as exclusion criteria. All adolescents and their parents gave written informed consent to participate after being fully briefed and informed of the study procedures. The trial was approved by the regional ethics board in compliance with the good clinical practice guidelines in the Declaration of Helsinki.

Study Design

After a medical examination to ensure their ability to complete the study, the adolescents were asked to attend two experimental sessions (7 days apart): i) anthropometric measurements, blood samplings, and maximal exercise tests; ii) a 40 -min constant power exercise $\left(70 \% \dot{V}_{2 \text { peak }}\right)$ during which microvascular and central adaptations were assessed. Both sessions were performed before $\left(\mathrm{W}_{0}\right)$ and after $\left(\mathrm{W}_{12}\right)$ a 12 -week intervention. The intervention consisted in a 12-week PA program (without dietary intervention) comprising 3 sessions of 90 min per week: i) endurance training using ergocycles and treadmills, starting at $50 \%$ to reach 
Julian et al.: Improving Peripheral and Central Vascular Adjustments during Exercise through a Training Program in Adolescents with Obesity

$80 \% \mathrm{~V}_{2 \text { peak }}$ by the end of the program; ii) a resistance-based exercise session (training circuit alternating upper and lower limbs exercise, with 10 repetitions per exercise, grading from 50 to $80 \%$ of the adolescent's 10 maximal repetitions; iii) the last session was mainly based on collective sports. Each missed session was caught up.

\section{Anthropometric Measurements and Body Composition}

Weight and height were measured with an accuracy of $0.1 \mathrm{~kg}$ and $0.5 \mathrm{~cm}$, respectively. Waist circumference was measured between the last ribs and the upper iliac wings with a flexible tape measure. Body composition was evaluated by dual energy X-ray absorptiometry (DXA; Hologic QDR-4500A, Bedford, MA, USA) $[15,16]$. The subjects laid on the DXA table in a supine position and remained still for the duration of the scanning procedure. Data was analyzed using the Hologic QDR Software for Windows (version 12.6), which integrates whole-body measurement and standard body regions, such as trunk, arms and legs, delineated by specific anatomical landmarks. From this the fat mass percentage by DXA was calculated. Thereafter, the percentage of abdominal fat mass was determined manually by a trained experimenter, by delineating a rectangular box around the region of interest between vertebral bodies L1 and L4. The upper limit was set with the horizontal line going through the T2/L1 vertebral space and the lowest limit was set with a horizontal line going through L4/L5 vertebral space [17]. This method has been previously used in obese youth [18].

\section{Blood Samplings}

Glycemia, insulinemia as well as plasma levels of total, LDL and HDL cholesterol, triglycerides and ultrasensitive C-reactive protein (us-CRP) were measured in venous blood in a fasting state at least $48 \mathrm{~h}$ after the last training session. LDL cholesterol was computed using the Friedwald's formula (LDL cholesterol (mmol/l) $=$ cholesterol total $(\mathrm{mmol} / \mathrm{l})-\mathrm{HDL}$ cholesterol $(\mathrm{mmol} / \mathrm{l})-$ triglyceride $(\mathrm{mmol} / \mathrm{l}) \times 0.5)$. Insulin resistance was expressed using the homeostasis model assessment of insuline resistance index (HOMA-IR = glycemia $(\mathrm{mmol} / \mathrm{l}) \times$ insulinemia $(\mathrm{mUI} / \mathrm{l}) / 22.5)[19]$.

\section{Maximal Incremental Exercise Test}

The initial power was set at $30 \mathrm{~W}$ during $3 \mathrm{~min}$ followed by a 15-watt increment every minute until exhaustion. The adolescents were strongly encouraged by the experimenters throughout the test to perform at maximal effort. Maximal criteria were: heart rate $(\mathrm{HR})>90 \%$ of the theoretical maximum heart rate $(210-0.65 \times$ age $)$, respiratory exchange ratio $\left(\mathrm{RER}=\dot{\mathrm{V}} \mathrm{CO}_{2} / \dot{\mathrm{VO}}_{2}\right)>1.1$ and/or $\dot{\mathrm{V}} \mathrm{O}_{2}$ plateau. Cardiac electrical activity was monitored (Ultima Series ${ }^{\mathrm{TM}}$; MGC Diagnostics, Saint Paul, MN, USA), and the test was coupled with a measurement of gas exchanges breath by breath (BreezeSuite Software; MGC Diagnostics) that determined respiratory minute volume ( $\dot{\mathrm{VE}})$, oxygen consumption $\left(\dot{\mathrm{VO}}_{2}\right)$ and $\mathrm{CO}_{2}$ production $\left(\dot{\mathrm{V}} \mathrm{CO}_{2}\right)$. Volumes and gases were calibrated before each test. The peak oxygen consumption $\left(\mathrm{V}_{2} \mathrm{O}_{2 \text { peak }}\right)$ was defined as the average of the last $30 \mathrm{~s}$ of exercise before exhaustion. The first ventilatory threshold (VT) was determined graphically by Wasserman's method and confirmed on the Beaver curve by two different operators [20, 21].

\section{0-min Constant Exercise}

After a 5-min rest period, the participants cycled for $40 \mathrm{~min}$ at a constant intensity close to VT (about $70 \% \mathrm{~V}_{2 \text { peak }}$ measured at $\mathrm{W}_{0}$ ). The children were strongly encouraged. The exact same exercise was performed before and after TP. Microvascular and central adaptations to exercise were measured concomitantly at rest and during the 40-min exercise.

Microvascular Adaptations

The blood volume and the oxygenation profile of skeletal muscle were monitored by near-infrared spectroscopy (NIRS) (Oxymon Mk III; Artinis Medical Systems, Elst, The Netherlands). The NIRS sensor was positioned on the bulk of the right Musculus vastus lateralis so that the center of the two optodes was located 15 $\mathrm{cm}$ above the upper edge of the kneecap, with the knee extended, parallel to the main axis of the muscle between the lateral epicondyl of the femur and the greater trochanter. The skin fold was measured at the point of fixation. Each NIRS probe comprised a transmitter and a receiver for two different wavelengths, 760 $\mathrm{nm}$ and $850 \mathrm{~nm}$. Inter-optode distance was $3.5 \mathrm{~cm}$. The differential path length factor was 4 . Two parameters were measured: muscle blood volume (IR-BV, the sum of the two absorbances at wavelengths 760 and 850 $\mathrm{nm}$ ) and tissue oxygen saturation (IR- $\mathrm{SO}_{2}$, the difference in absorbance at the two wavelengths). The data were collected at a frequency of $10 \mathrm{~Hz}$, and averaged every $30 \mathrm{~s}$. The results were expressed relative to the 
Table 1. Anthropometric measurements, body composition and blood chemistry values at week $0\left(\mathrm{~W}_{0}\right)$ and week $12\left(\mathrm{~W}_{12}\right)(\mathrm{n}=15$; mean $\pm \mathrm{SD})$
Julian et al.: Improving Peripheral and Central Vascular Adjustments during Exercise through a Training Program in Adolescents with Obesity

\begin{tabular}{llll}
\hline & $\mathrm{W}_{0}$ & $\mathrm{~W}_{12}$ & $\mathrm{p}$ value \\
\hline Weight, kg & $87.2 \pm 11.6$ & $83.4 \pm 11.8$ & 0.001 \\
Height, cm & $161 \pm 8$ & $161 \pm 8$ & 0.41 \\
BMI, kg/m ${ }^{2}$ & $33.6 \pm 3.9$ & $32.0 \pm 3.8$ & $<0.001$ \\
Waist circumference, cm & $102.4 \pm 17.0$ & $98.6 \pm 17.5$ & $<0.001$ \\
Lean body mass, kg & $51.5 \pm 8.1$ & $51.6 \pm 8.5$ & 0.72 \\
Total fat mass, kg & $35.3 \pm 5.7$ & $29.6 \pm 9.8$ & $<0.001$ \\
Percent body fat, \% & $40.1 \pm 4.3$ & $37.2 \pm 4.9$ & $<0.001$ \\
Abdominal mass, kg & $5.7 \pm 1.5$ & $5.5 \pm 1.4$ & 0.03 \\
Abdominal lean mass, kg & $3.3 \pm 0.7$ & $3.4 \pm 0.7$ & 0.84 \\
Abdominal fat mass, kg & $2.4 \pm 1.0$ & $2.1 \pm 0.9$ & $<0.001$ \\
Abdominal fat mass, \% & $40.6 \pm 6.9$ & $36.7 \pm 8.0$ & $<0.001$ \\
Insulinemia, mUI/l & $21.7 \pm 14.0$ & $18.1 \pm 11.2$ & 0.11 \\
Glycemia, mmol/l & $4.46 \pm 0.50$ & $4.13 \pm 0.84$ & 0.02 \\
HOMA-IR & $4.30 \pm 3.18$ & $3.58 \pm 2.85$ & 0.07 \\
Total cholesterol, mmol/l & $3.59 \pm 0.93$ & $3.89 \pm 0.56$ & 0.13 \\
LDL cholesterol, mmol/l & $2.32 \pm 0.76$ & $2.33 \pm 0.61$ & 0.94 \\
HDL cholesterol, mmol/l & $0.97 \pm 0.19$ & $1.06 \pm 0.17$ & 0.04 \\
Triglycerides, mmol/l & $1.24 \pm 0.92$ & $1.00 \pm 0.44$ & 0.82 \\
us-CRP, mg/l & $2.60 \pm 1.41$ & $1.13 \pm 1.18$ & 0.04 \\
\hline
\end{tabular}

us-CRP = Ultrasensitive C-reactive protein; HOMA-IR = homeostasis model assessment of insulin resistance.

average resting value: the value 0 was thus arbitrarily taken for the start of the exercise. The variations in IR-BV and $\mathrm{IR}-\mathrm{SO}_{2}$ gave a continuous estimate of the regional changes in blood volume and the local balance between oxygen delivery to muscle and its extraction by muscle [22]. Kinetics of IR-BV and IR- $\mathrm{SO}_{2}$ at $\mathrm{W}_{0}$ and $\mathrm{W}_{12}$ were compared.

Central Vascular Adaptations

The cardiac output (CO) was measured continuously by PF05 Lab1 ${ }^{\mathrm{TM}}$,(PhysioFlow, Bristol, PA, USA). The stroke volume (SV) was calculated from the measurement of variations in thoracic bioimpedance fluctuations [23]. HR, SV, and CO were averaged over $30 \mathrm{~s}$.

In all, the parameters collected over the exercise at constant power were: IR-BV(t), IR-SO $\mathrm{S}_{2}(\mathrm{t}), \mathrm{HR}(\mathrm{t})$, $\mathrm{SV}(\mathrm{t})$, and $\mathrm{CO}(\mathrm{t})$.

\section{Statistical Analysis}

Sample size estimation has been initially proposed to show an important effect size around 1, according to Cohen's recommendations [24]. Also, with $n=13$ subjects, an effect size equaling 1 can be highlighted for a two-sided type I error at 5\% and a statistical power at $90 \%$. Finally, 15 subjects have been included to take into account possible lost to follow-up.

Statistical analysis was performed using Stata software, version 13 (StataCorp, College Station, TX, USA). The tests were two-sided, with a type I error set at $\alpha=0.05$. Data were presented as the mean \pm standard deviation or the median (interquartile range) according to statistical distribution (assumption of normality studied by Shapiro-Wilk test). For paired comparisons between $\mathrm{W}_{0}$ or $\mathrm{W}_{12}$, usual statistical tests were performed: paired t-test or Wilcoxon test for quantitative variables and Stuart-Maxwell's test for categorical parameters. Concerning repeated correlated data (parameters measured longitudinally such as IR-BV, IR-SO $\mathrm{S}_{2}, \mathrm{HR}, \mathrm{SV}$, and $\mathrm{CO}$ ), mixed models (linear for continuous dependent variable with log-transformation to achieve normality when appropriate) have been proposed in order to take into account the between and within subject variability (random effect) while studying impact of fixed effects: group $\left(\mathrm{W}_{0}\right.$ or $\left.\mathrm{W}_{12}\right)$, time point evaluation and their interaction. When $\mathrm{p}$ value associated to interactions were $<0.05$, subgroup analyses were proposed. The normality of residuals was studied for each of the models. 
Julian et al.: Improving Peripheral and Central Vascular Adjustments during Exercise through a Training Program in Adolescents with Obesity

Table 2. Functional results of maximal incremental exercise test at week $0\left(\mathrm{~W}_{0}\right)$ and week $12\left(\mathrm{~W}_{12}\right)(\mathrm{n}=15$; mean \pm SD)

\begin{tabular}{llll}
\hline & $\mathrm{W}_{0}$ & $\mathrm{~W}_{12}$ & $\mathrm{p}$ value \\
\hline Pmax, W & $133.5 \pm 30.8$ & $154.0 \pm 31.5$ & 0.0003 \\
Relative Pmax, W/kg body mass & $1.53 \pm 0.29$ & $1.86 \pm 0.36$ & 0.0003 \\
$\dot{\mathrm{V}} \mathrm{O}_{2 \text { peak }} \mathrm{l} / \mathrm{min}$ & $1.9 \pm 0.3$ & $2.0 \pm 0.4$ & 0.22 \\
Indexed $\dot{\mathrm{V}} \mathrm{O}_{2 \max }, \mathrm{l} / \mathrm{min} / \mathrm{kg}$ body mass & $22.6 \pm 3.6$ & $24.6 \pm 4.5$ & 0.008 \\
$\dot{\mathrm{V} E m a x}, \mathrm{l} / \mathrm{min}$ & $73.6 \pm 12.7$ & $77.1 \pm 14.8$ & 0.17 \\
$\mathrm{RERmax}$ & $1.13 \pm 0.06$ & $1.17 \pm 0.06$ & 0.03 \\
$\mathrm{HRmax}, \mathrm{bpm}$ & $186 \pm 11.4$ & $181 \pm 14.0$ & 0.02 \\
$\mathrm{P}$ VT, W & $88.2 \pm 24.2(90.0)$ & $107.1 \pm 30.4(105)$ & 0.0004 \\
$\dot{\mathrm{V}} \mathrm{O}_{2} \mathrm{VT}, \mathrm{l} / \mathrm{min}$ & $1.30 \pm 0.25(1.3)$ & $1.46 \pm 0.32(1.4)$ & 0.03 \\
\hline
\end{tabular}

$\mathrm{HR}=$ Heart rate; $\mathrm{P}=$ power output; $\mathrm{RER}=$ respiratory exchange ratio; $\dot{\mathrm{V}} \mathrm{E}=$ minute ventilation; $\dot{\mathrm{V}} \mathrm{O}_{2}=$ oxygen consumption; VT = ventilatory threshold.

\section{Results}

15 adolescents ( 4 boys and 11 girls) met the inclusion criteria and enrolled the study. Their program attendance was $100 \%$.

\section{Anthropometric and Biological Parameters}

The adolescents' mean age was $13.8 \pm 1.7$ years. The main anthropometric characteristics are given in table 1 . The absolute weight loss after training was $3.8 \pm 3.5 \mathrm{~kg}(-4.3 \%)$, with a significant decrease in BMI, waist circumference, and both total and abdominal fat mass, but no loss of lean mass.

Biological parameters are given in table 1. We noted a significant increase in HDL cholesterol and a significant decrease in us-CRP. A trend for the decrease in HOMA-IR was recorded after TP ( $p=0.07)$, with a significant reduction of fasting glycemia and a nonsignificant reduction of insulinemia.

\section{Maximal Aerobic Capacity}

Functional parameters are given in table 2. Maximal power output (Pmax) increased significantly after TP. $\dot{\mathrm{V}} \mathrm{O}_{2 \text { peak }}$ increased significantly relative to body mass but not significantly in absolute value. VT was shifted graphically rightwards, as shown by the significant increase in $\mathrm{P}$ and $\dot{\mathrm{VO}}_{2}$ at VT.

\section{Central Vascular Adaptations during Constant Exercise}

The average workload during exercise was $73 \pm 12 \mathrm{~W}$, which corresponds to a $\mathrm{VO}_{2}$ value at $69 \%$ and $65 \%$ of $\dot{V} O_{2 \text { peak }}$ measured at $W_{0}$ and $W_{12}$, respectively. The average time course kinetics of $\mathrm{HR}, \mathrm{SV}$, and $\mathrm{CO}$ at $\mathrm{W}_{0}$ and $\mathrm{W}_{12}$ are given in figure 1 . These parameters decreased significantly $(\mathrm{p}<0.001)$ after TP. Their average values over the whole duration of the exercise were $148 \pm 21 \mathrm{bpm}$ at $W_{0}$ and $140 \pm 19 \mathrm{bpm}$ at $W_{12}$ for $H R, 105 \pm 19 \mathrm{ml}$ at $W_{0}$ and $103 \pm 19$ $\mathrm{ml}$ at $\mathrm{W}_{12}$ for $\mathrm{SV}$, and $15.5 \pm 3.3 \mathrm{l} / \mathrm{min}$ at $\mathrm{W}_{0}$ and $14.4 \pm 2.7 \mathrm{l} / \mathrm{min}$ at $\mathrm{W}_{12}$ for $\mathrm{CO}$.

Microvascular Adaptations in the M. vastus lateralis during Constant Exercise

The average time course kinetics of IR-BV and IR-SO $\mathrm{S}_{2}$ before and after TP are shown in figure 2. At both $\mathrm{W}_{0}$ and $\mathrm{W}_{12}$, the parameters are described in three phases: phase 1 (time 
Julian et al.: Improving Peripheral and Central Vascular Adjustments during Exercise through a Training Program in Adolescents with Obesity

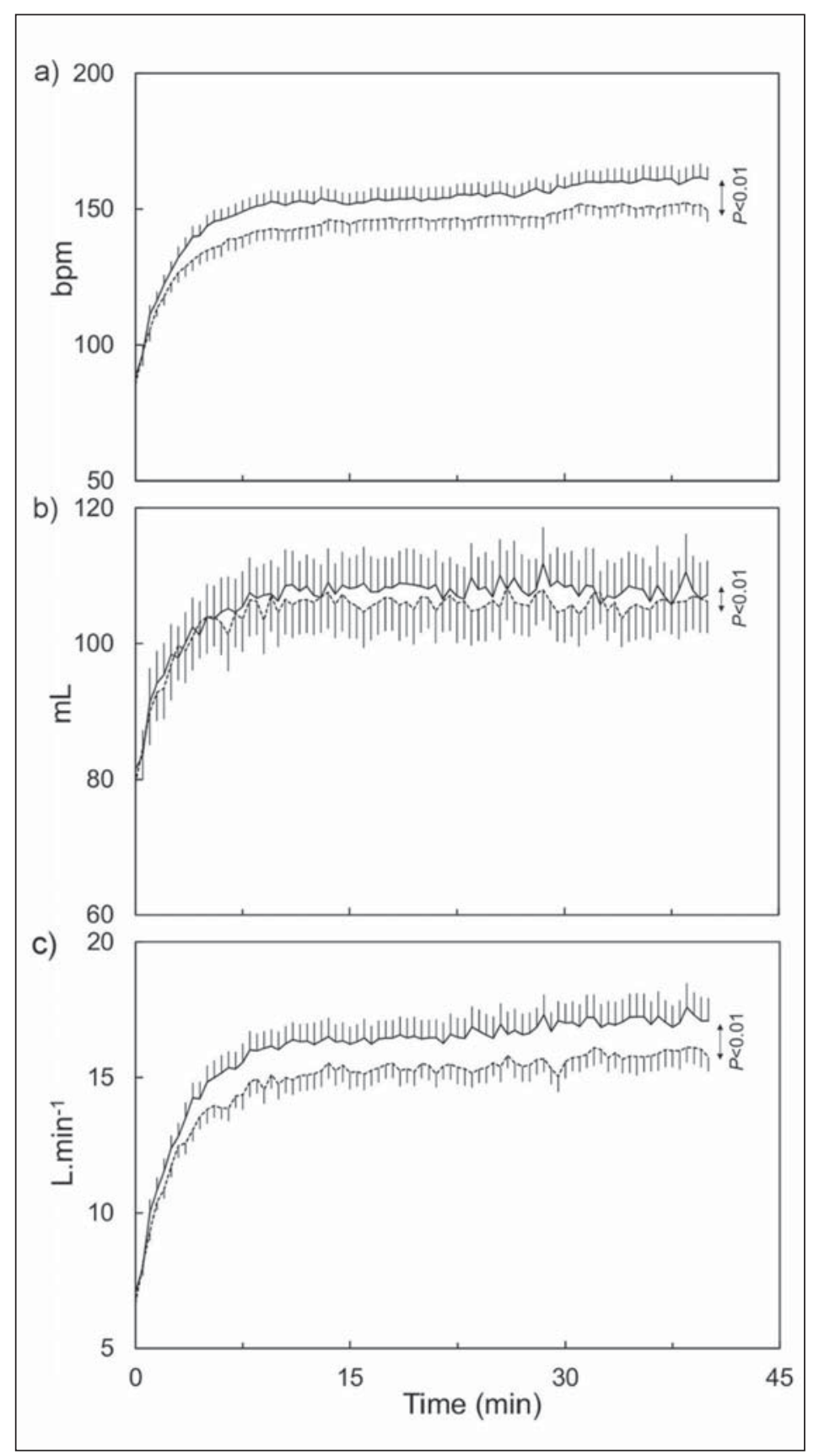

Fig. 1. Average time course kinetics of $\mathbf{a} \mathrm{HR}, \mathbf{b} \mathrm{SV}$ and $\mathbf{c} \mathrm{CO}$ during exercise lasting $40 \mathrm{~min}$ at constant intensity, at $\mathrm{W}_{0}$ (continuous line) and $\mathrm{W}_{12}$ (dotted line). The parameter values are expressed as average \pm standard error $(n=$ 15) and were compared between $\mathrm{W}_{0}$ and $\mathrm{W}_{12}$.

interval for which the relative values are significantly lower than the base value), phase 2 (time interval for which the relative values are not significantly different from the base value), and phase 3 (time interval for which the relative values are significantly higher than the base value). At both $\mathrm{W}_{0}$ and $\mathrm{W}_{12}$, after $30 \mathrm{~s}$ of exercise, there was a significant reduction of IR-BV and $\mathrm{IR}-\mathrm{SO}_{2}$, with a nadir reached 1 min after the start of the exercise. During phase 3 , the increase in values was constant until the end of exercise with no plateau. All times take together, IR-BV and IR-SO ${ }_{2}$ were significantly higher at $\mathrm{W}_{12}(\mathrm{p}<0.001)$, with differences in time course during the different phases. 
Julian et al.: Improving Peripheral and Central Vascular Adjustments during Exercise through a Training Program in Adolescents with Obesity

Fig. 2. Average time course kinetics of muscle blood volume (IR$\mathrm{BV}$ ) (a) and tissue oxygen saturation (IR-SO ${ }_{2}$ ) (b) in the M. vastus lateralis during the 40 min exercise at constant power, at $\mathrm{W}_{0}$ (continuous line) and $\mathrm{W}_{12}$ (dotted line) $(\mathrm{n}=15)$. IR-BV and IR-SO are expressed relative to base values, average \pm standard error. For each time, IR-BV(t) and IR-SO $2(\mathrm{t})$ were compared with their base value (double horizontal arrows) and between $W_{0}$ and $W_{12}$ (vertical double arrows).
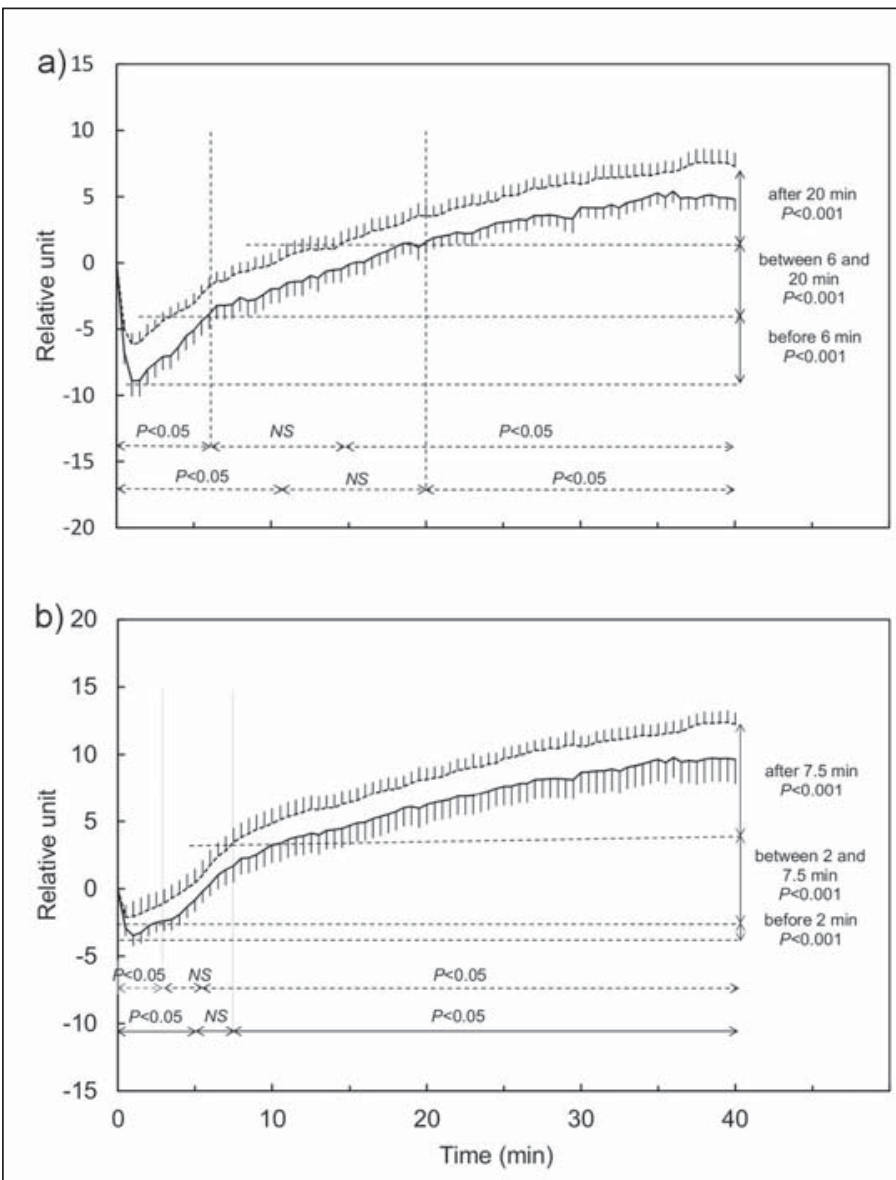

During phase 1, we found a prompter return to base IR-BV (10 $\mathrm{min}$ at $\mathrm{W}_{0}$ and $6 \mathrm{~min}$ at $\left.\mathrm{W}_{12}\right)$, a significantly higher nadir $\left(-8.6 \pm 3.7\right.$ at $\mathrm{W}_{0,},-5.7 \pm 2.8$ at $\left.\mathrm{W}_{12,} \mathrm{p}=0.017\right)$, and a significantly higher IR-BV(t) $(\mathrm{p}<0.001)$ after TP. During phases 2 and 3, IR-BV(t) was significantly higher after TP $(\mathrm{p}<0.001)$.

Moreover, during phase 1 , we observed a prompter return to base $\mathrm{IR}-\mathrm{SO}_{2}\left(5 \mathrm{~min}\right.$ at $\mathrm{W}_{0}$ and 2 min at $\left.\mathrm{W}_{12}\right)$, a significantly higher nadir $\left(-3.8 \pm 2.3\right.$ to $\mathrm{W}_{0},-2.3 \pm 1.9$ at $\left.\mathrm{W}_{12} ; \mathrm{p}=0.01\right)$, and a significantly higher IR-SO ${ }_{2}(\mathrm{t})(\mathrm{p}<0.001)$ after TP. During phases 2 and $3, \mathrm{IR}^{-\mathrm{SO}_{2}}(\mathrm{t})$ was significantly higher after TP $(\mathrm{p}<0.001)$.

There was no modification of blood hemoglobin concentration after TP $(12.9 \pm 0.8 \mathrm{~g} / \mathrm{dl}$ at $W_{0}, 13.0 \pm 0.5 \mathrm{~g} / \mathrm{dl}$ at $\left.\mathrm{W}_{12}, \mathrm{p}=0.24\right)$. The fat thickness at the point of fixation of NIRS was $16.3 \pm 7.5 \mathrm{~mm}$ at $\mathrm{W}_{0}$ and $16.1 \pm 7.7 \mathrm{~mm}$ at $\mathrm{W}_{12}(\mathrm{p}=0.62)$.

\section{Correlation between Microvascular Adaptations and HOMA-IR}

There was no significant correlation between the increase in IR-BV and $\mathrm{IR}_{-} \mathrm{SO}_{2}$ and the decrease in HOMA-IR after TP, at any time or for all times taken together for the 40 min of exercise (no correlations either with fasting glycemia or fasting insulinemia or waist circumference or abdominal fat mass). 
Julian et al.: Improving Peripheral and Central Vascular Adjustments during Exercise through a Training Program in Adolescents with Obesity

\section{Discussion}

The main goal of this study was to measure the impact of a 12-week TP on microvascular adaptations to exercise in adolescents with obesity by noninvasive techniques. The study shows that the program increases microvascularization during exercise and speeds peripheral vascular adaptations at the start of exercise, causing less initial de-oxygenation and a prompter response of the muscle to the metabolic demand. This is the first prospective trial that evaluates the effects of training in adolescents with obesity on vascular adaptations to exercise using NIRS. Muscle blood volume kinetics and muscle oxygenation profile obtained by NIRS are fully consistent with those obtained by Costes et al. [25] in healthy adults with 15-min exercises at a constant intensity of $50 \%$ and $80 \%$ of $\dot{V}_{2 \text { peak }}$, showing a nadir within the first few minutes and gradual tissue re-oxygenation associated with a new increase in blood volume. Variations in temperature and skin hydration during long-duration exercises can modify optical parameters [26], which can explain the drift in NIRS values at the end of the exercise. However, this does not affect the general kinetics observed and the comparison before and after TP. We would like to remind you to keep in mind that NIRS reflects only microcirculatory adjustments at the muscle periphery and is not directly informative about deep vascular adaptations. It has been shown that in subjects with obesity, subcutaneous fat prevents some of the infrared radiation from being transmitted to the muscle [26]. Although one could argue that adipose tissue thickness can limit our measure, it has been assessed using a B-mode ultrasound device at the point of fixation of NIRS optodes in a gender- BMIand aged-matched population of 10 adolescents. The subcutaneous thickness was $13.4 \pm 0.2$ $\mathrm{mm}$, which matches with the skin fold measured before and after TP. Since the penetration depth of the light is estimated between 15 and $20 \mathrm{~mm}$ (half of inter-optode distance), we thus can consider that NIRS measured effectively muscular microvascularization and that adipose thickness is not a limiting factor. The NIRS signal reflects the balance between $\mathrm{O}_{2}$ delivery and $\mathrm{O}_{2}$ consumption but different mechanisms can be involved in the increase in microvascularization. Particularly, NIRS signal cannot distinguish vasodilatation or neocapillarization induced by training [27]. Additional histological analysis on muscle biopsies would yield more information, but would be problematic in clinical research on children. NIRS is a noninvasive alternative technique, well accepted, and painless. It has been used recently to detect oxidative skeletal muscle impairments during exercise in children with hematological cancers [28], but not in obese children.

Concerning the secondary objective, we only found a trend for the decrease in HOMA-IR $(\mathrm{p}=0.07)$. This can be explained by the low sample size and the high interindividual variability in HOMA-IR, although this noninvasive technique was closely correlated with the reference euglycemic hyperinsulinemic clamp technique [29]. The decrease in HOMA-IR is still an important finding insofar as this parameter is considered as an independent predictive factor of cardiovascular risk [19]. For the HOMA-IR index, the variation before and after the TP is $-24 \%$ (range $-47 ; 20 \%$ ). As indicated by Feise [30], one must be careful to not only focusing upon statistical significance, but also upon the quality of the research within the study and the magnitude of differences. However, it was recently shown that HOMA-IR reflected hepatic rather than muscular insulin resistance [31]. Postprandial measurement of the insulinemia/glycemia ratio would have been technically too complex to be carried out here (duration of experimentation, standardization of meals, repeated blood sampling etc.). Microvascular improvements during exercise may be the direct outcome of TP; it has been demonstrated in adults that 16 weeks of endurance training increased the number of capillaries per muscle fiber measured on biopsies of the M. vastus lateralis [32]. A recent metaanalysis [33] has demonstrated that flow-mediated dilation is improved in overweight and obese children, but this study does not directly attest the capillary adjustments in response 
to exercise. The hypothesis of an insulin-dependent increase in muscle microvascularization as suggested in adults through invasive methods cannot be ruled out. It was recently demonstrated that the increased capillary density induced by endurance training lasting 6 months and measured on biopsies in insulin-resistant adults was correlated with a reduction of insulin resistance measured using the clamp technique, independently of improvements in the subjects' body composition and aerobic capacity [34]. It may therefore be possible that the choice of technique is responsible for the absence of any correlation in our study. Although many trials have evidenced the insulin dependency mechanisms underlying increased microvascularization [5, 7, 8, 35], correlation between these parameters in no sense proves causality.

Regarding methodology, the lack of a control group composes the main limitation of the present work. The before-and-after profile of the study was emphasized in view of national ethical considerations, which place physical activity at the cornerstone of healthcare for obesity. Although making up a control group of unmanaged obese adolescents would have been scientifically useful, it is ethically problematic to make clinical measurements in adolescents who need healthcare for obesity in a specialized center without actually offering it. The 'pre-post' nature of this work provides however relatively strong evidence regarding the effect of our intervention, especially when looking at the length of the intervention (the short duration of the program limits any effects of the maturation process on our results).

Nevertheless, anthropometric, biological, and functional improvements after TP attest to the already advanced multitarget effect of PA in children. Reduced waist circumference and decreased total and abdominal fat mass without loss of lean mass are excellent markers of reduced metabolic risk [36, 37]. Reduction of us-CRP also indicates a reduction in low-grade inflammation that favors atherosclerosis and insulin resistance in obesity $[3,35,38]$. The increase in HDL cholesterol and the $20 \%$ drop in plasma triglyceride levels are also consistent with literature reports [39]. The gain of $9 \%$ in aerobic capacity relative to body mass and the shift of VT is indicative of greater endurance in daily-life activities, which is very important because aerobic capacity measurements are now considered as major independent predictive parameters of mortality in adult and pediatric subjects presenting with cardiovascular risk factors $[40,41]$. Central vascular adaptations observed during the constant exercise (diminution after TP by $6 \%$ in HR and 8\% in CO) are also consistent with an impact of training on cardiovascular parameters as recently described [42,43]. The lowering of $\mathrm{CO}$ was observed concomitantly with the increased blood volume in the M. vastus lateralis, reflecting an improvement in the distribution of blood flow with exercise after TP. However, it is important to underline that the average weight loss observed in the adolescent groups studied might have had consequences on the physiological adaptations during exercise, and we therefore cannot totally dissociate effects linked to training alone from those linked to weight loss. In addition, we would like to mention that TP was not associated with any recommendations in terms of energy restrictions. It was shown that muscle oxygenation and blood flow measured by NIRS during an endurance exercise changed after training in healthy adults [25]. These adaptations confirmed the well-known training-induced improvements in capillarization and oxidative capacities, as muscles are the main consumer of glucose and fatty acids [44]. To the best of our knowledge, this has never been demonstrated in obese adults or in obese children. However, these adaptations could be used as a noninvasive index of a muscle training effect. Using noninvasive measurements, we demonstrated increases in oxygen extraction and utilization via central and peripheral blood flow adjustments during the exercise. This is of clinical interest in order to ascertain the benefits of such TPs and to reinforce the compliance of obese adolescents with combined training (endurance and resistance twice a week, plus one session of collective sport) in a real-life setting. 
Julian et al.: Improving Peripheral and Central Vascular Adjustments during Exercise through a Training Program in Adolescents with Obesity

Our trial demonstrates that a 12-week TP combining endurance and muscle strengthening induces an increased microvascularization of exercised lower limbs. In addition, we could show both peripheral and central adaptations due to the TP resulting in improvements in the distribution of blood flow with exercise after TP. These improvements of anthropometric, biological parameters and aerobic capacities thus are strong proofs in favor of generalizing this type of healthcare in adolescents with obesity. The mechanisms that account for vascular improvements, in particular the role of insulin, need further investigations on a greater number of patients. An understanding of the mechanisms induced by PA is an indispensable requirement for guiding its prescription with respect to type, intensity, and duration of exercise.

\section{Funding}

No funding.

\section{Disclosure Statement}

The authors declare no conflict of interest.

\section{References}

1 Freedman DS, Katzmarzyk PT, Dietz WH, Srinivasan SR, Berenson GS: Relation of body mass index and skinfold thicknesses to cardiovascular disease risk factors in children: the Bogalusa Heart Study. Am J Clin Nutr 2009; 90:210-216.

-2 Tirosh A, Shai I, Afek A, Dubnov-Raz G, Ayalon N, Gordon B, et al: Adolescent BMI trajectory and risk of diabetes versus coronary disease. N Engl J Med 2011;364:1315-1325.

-3 Fernhall B, Agiovlasitis S: Arterial function in youth: window into cardiovascular risk. J Appl Physiol (1985) 2008;105:325-333.

4 Janssen I, Leblanc AG: Systematic review of the health benefits of physical activity and fitness in school-aged children and youth. Int J Behav Nutr Phys Act 2010;7:40.

5 Vincent MA, Clerk LH, Lindner JR, Price WJ, Jahn LA, Leong-Poi H, et al: Mixed meal and light exercise each recruit muscle capillaries in healthy humans. Am J Physiol Endocrinol Metab 2006;290:E1191-1197.

6 Barrett EJ, Wang H, Upchurch CT, Liu Z: Insulin regulates its own delivery to skeletal muscle by feed-forward actions on the vasculature. Am J Physiol Endocrinol Metab 2011;301:E252-263.

-7 Wang H, Liu Z, Li G, Barrett EJ: The vascular endothelial cell mediates insulin transport into skeletal muscle. Am J Physiol Endocrinol Metab 2006;291:E323-332.

-8 Keske MA, Clerk LH, Price WJ, Jahn LA, Barrett EJ: Obesity blunts microvascular recruitment in human forearm muscle after a mixed meal. Diabetes Care 2009;32:1672-1677.

-9 Womack L, Peters D, Barrett EJ, Kaul S, Price W, Lindner JR: Abnormal skeletal muscle capillary recruitment during exercise in patients with type 2 diabetes mellitus and microvascular complications. J Am Coll Cardiol 2009;53:2175-2183.

10 Bell LM, Watts K, Siafarikas A, Thompson A, Ratnam N, Bulsara M, et al: Exercise alone reduces insulin resistance in obese children independently of changes in body composition. J Clin Endocrinol Metab 2007;92: 4230-4235.

11 BenOunis O, Elloumi M, Ben Chiekh I, Zbidi A, Amri M, Lac G, et al: Effects of two-month physical-endurance and diet-restriction programmes on lipid profiles and insulin resistance in obese adolescent boys. Diabetes Metab 2008;34:595-600.

-12 Jiménez-Pavón D, Ruiz JR, Ortega FB, Martínez-Gómez D, Moreno S, Urzanqui A, et al: Physical activity and markers of insulin resistance in adolescents: role of cardiorespiratory fitness levels - the HELENA study. Pediatr Diabetes 2013;14:249-258.

-13 Ottevaere C, Huybrechts I, De Bourdeaudhuij I, Sjöström M, Ruiz JR, Ortega FB, et al: Comparison of the IPAQ-A and actigraph in relation to V02max among European adolescents: the HELENA study. J Sci Med Sport 2011; 14:317-324.

14 Rolland-Cachera MF, Cole TJ, Sempé M, Tichet J, Rossignol C, Charraud A: Body mass index variations: centiles from birth to 87 years. Eur J Clin Nutr 1991;45:13-21.

15 Bachrach LK, Sills IN, Section on Endocrinology: Clinical report - bone densitometry in children and adolescents. Pediatrics 2011;127:189-194. 
Julian et al.: Improving Peripheral and Central Vascular Adjustments during Exercise through a Training Program in Adolescents with Obesity

Kamel EG, McNeill G, Han TS, Smith FW, Avenell A, Davidson L, et al: Measurement of abdominal fat by magnetic resonance imaging, dual-energy X-ray absorptiometry and anthropometry in non-obese men and women. Int J Obes Relat Metab Disord 1999;23:686-692.

17 Glickman SG, Marn CS, Supiano MA, Dengel DR: Validity and reliability of dual-energy X-ray absorptiometry for the assessment of abdominal adiposity. J Appl Physiol 1985 2004;97:509-514.

18 Aucouturier J, Meyer M, Thivel D, Taillardat M, Duché P: Effect of android to gynoid fat ratio on insulin resistance in obese youth. Arch Pediatr Adolesc Med 2009;163:826-831.

19 Bonora E, Formentini G, Calcaterra F, Lombardi S, Marini F, Zenari L, et al: HOMA-estimated insulin resistance is an independent predictor of cardiovascular disease in type 2 diabetic subjects: prospective data from the Verona Diabetes Complications Study. Diabetes Care 2002;25:1135-1141.

20 Beaver WL, Wasserman K, Whipp BJ: A new method for detecting anaerobic threshold by gas exchange. J Appl Physiol 1985 1986;60:2020-2027.

-21 Wasserman K, Stringer WW, Casaburi R, Koike A, Cooper CB: Determination of the anaerobic threshold by gas exchange: biochemical considerations, methodology and physiological effects. Z Kardiol 1994;83(suppl 3):1-12.

22 Boushel R, Langberg H, Olesen J, Gonzales-Alonzo J, Bülow J, Kjaer M: Monitoring tissue oxygen availability with near infrared spectroscopy (NIRS) in health and disease. Scand J Med Sci Sports 2001;11:213-222.

-23 Charloux A, Lonsdorfer-Wolf E, Richard R, Lampert E, Oswald-Mammosser M, Mettauer B, et al: A new impedance cardiograph device for the non-invasive evaluation of cardiac output at rest and during exercise: comparison with the 'direct' Fick method. Eur J Appl Physiol 2000;82:313-320.

24 Cohen J: Statistical Power Analysis for the Behavioral Sciences, 2nd ed. Hillsdale, Erlbaum, 1988.

-25 Costes F, Prieur F, Féasson L, Geyssant A, Barthélémy JC, Denis C: Influence of training on NIRS muscle oxygen saturation during submaximal exercise. Med Sci Sports Exerc 2001;33:1484-1489.

-26 Ferrari M, Muthalib M, Quaresima V: The use of near-infrared spectroscopy in understanding skeletal muscle physiology: recent developments. Philos Transact A Math Phys Eng Sci 2011;369:4577-4590.

27 McCully KK, Hamaoka T: Near-infrared spectroscopy: what can it tell us about oxygen saturation in skeletal muscle? Exerc Sport Sci Rev 2000;28:123-127.

28 Lanfranconi F, Pollastri L, Ferri A, Fraschini D, Masera G, Miserocchi G: Near infrared spectroscopy (NIRS) as a new non-invasive tool to detect oxidative skeletal muscle impairment in children survived to acute lymphoblastic leukaemia. PloS One 2014;9:e99282.

29 Henderson M, Rabasa-Lhoret R, Bastard J-P, Chiasson J-L, Baillargeon J-P, Hanley JA, et al: Measuring insulin sensitivity in youth: how do the different indices compare with the gold-standard method? Diabetes Metab 2011;37:72-78

30 Feise RJ: Do multiple outcome measures require p-value adjustment? BMC Med Res Methodol 2002;2:8.

-31 Tripathy D, Almgren P, Tuomi T, Groop L: Contribution of insulin-stimulated glucose uptake and basal hepatic insulin sensitivity to surrogate measures of insulin sensitivity. Diabetes Care 2004;27:2204-2210.

-32 Hansen AH, Nielsen JJ, Saltin B, Hellsten Y: Exercise training normalizes skeletal muscle vascular endothelial growth factor levels in patients with essential hypertension. J Hypertens 2010;28:1176-1185.

33 Dias KA, Green DJ, Ingul CB, Pavey TG, Coombes JS: Exercise and vascular function in child obesity: a metaanalysis. Pediatrics 2015;136:e648-659.

-34 Prior SJ, Blumenthal JB, Katzel LI, Goldberg AP, Ryan AS: Increased skeletal muscle capillarization after aerobic exercise training and weight loss improves insulin sensitivity in adults with IGT. Diabetes Care 2014;37:14691475.

-35 Barrett EJ, Eringa EC: The vascular contribution to insulin resistance: promise, proof, and pitfalls. Diabetes 2012;61:3063-3065

36 Kay SJ, Fiatarone Singh MA: The influence of physical activity on abdominal fat: a systematic review of the literature. Obes Rev 2006;7:183-200.

37 LeMura LM, Maziekas MT: Factors that alter body fat, body mass, and fat-free mass in pediatric obesity. Med Sci Sports Exerc 2002;34:487-496.

38 Balagopal P, George D, Patton N, Yarandi H, Roberts WL, Bayne E, et al: Lifestyle-only intervention attenuates the inflammatory state associated with obesity: a randomized controlled study in adolescents. J Pediatr 2005; 146:342-348.

-39 Monzavi R, Dreimane D, Geffner ME, Braun S, Conrad B, Klier M, et al: Improvement in risk factors for metabolic syndrome and insulin resistance in overweight youth who are treated with lifestyle intervention. Pediatrics 2006;117:e1111-1118.

40 Myers J, Prakash M, Froelicher V, Do D, Partington S, Atwood JE: Exercise capacity and mortality among men referred for exercise testing. $\mathrm{N}$ Engl J Med 2002;346:793-801.

-41 Ruiz JR, Castro-Piñero J, Artero EG, Ortega FB, Sjöström M, Suni J, et al: Predictive validity of health-related fitness in youth: a systematic review. Br J Sports Med 2009;43:909-923.

42 Blomqvist CG, Saltin B: Cardiovascular adaptations to physical training. Annu Rev Physiol 1983;45:169-189.

-43 Tulppo MP, Mäkikallio TH, Seppänen T, Laukkanen RT, Huikuri HV: Vagal modulation of heart rate during exercise: effects of age and physical fitness. Am J Physiol 1998;274:H424-429.

-44 Stinkens R, Goossens GH, Jocken JWE, Blaak EE: Targeting fatty acid metabolism to improve glucose metabolism. Obes Rev 2015;16:715-757. 